Case Report

\title{
A Rare Complication of Biliary Stent Migration: Small Bowel Perforation in a Patient with Incisional Hernia
}

\author{
Özkan Yilmaz, ${ }^{1}$ Remzi Kiziltan, ${ }^{1}$ Oktay Aydin, ${ }^{2}$ Vedat Bayrak, ${ }^{3}$ and Çetin Kotan ${ }^{1}$ \\ ${ }^{1}$ Department of General Surgery, Faculty of Medicine, Yüzüncü Yıl University, Van, Turkey \\ ${ }^{2}$ Department of General Surgery, Faculty of Medicine, Kirıkale University, Kirıkkale, Turkey \\ ${ }^{3}$ Department of General Surgery, Ceyhan Government Hospital, Adana, Turkey
}

Correspondence should be addressed to Özkan Yilmaz; drozyilmaz@gmail.com

Received 12 March 2015; Revised 8 July 2015; Accepted 9 July 2015

Academic Editor: Steve de Castro

Copyright ( 2015 Özkan Yilmaz et al. This is an open access article distributed under the Creative Commons Attribution License, which permits unrestricted use, distribution, and reproduction in any medium, provided the original work is properly cited.

Endoscopic biliary stents have been recently applied with increasing frequency as a palliative and curable method in several benign and malignant diseases. As a reminder, although most of the migrated stents pass through the intestinal tract without symptoms, a small portion can lead to complications. Herein, we present a case of intestinal perforation caused by a biliary stent in the hernia of a patient with a rarely encountered incarcerated incisional hernia.

\section{Introduction}

Endoscopic biliary stents have been recently applied with increasing frequency for several benign and malignant diseases. This procedure presents short-term complications such as hemorrhage, pancreatitis, cholangitis, and perforation, in addition to long-term complications such as stent migration and late perforation [1]. In this case report, we present a case of intestinal perforation caused by a biliary stent in the hernia of a patient with a rarely encountered incarcerated incisional hernia.

\section{Case Presentation}

A 52-year-old female patient was admitted to the emergency department with complaints of abdominal pain and the inability to pass gas and stools for two days. The patient received endoscopic retrograde cholangiopancreatography (ERCP) and a biliary stent procedure three years prior due to choledocholithiasis, after which she was surgically treated with a median incision due to a cyst in the liver one and a half years prior. The ERCP was repeated and the stent was replaced due to cholestasis symptoms three months prior to the current presentation. Upon inspection of the patient, a painful-upon-palpation, $10 \mathrm{~cm}$ in diameter, irreducible hernia sac with an erythematous surface was palpable, which had herniated from the $4 \mathrm{~cm}$ fascial defect at the bottom of the patient's midline incision. Upon discovery of edematous bowel loops and $10 \times 5 \mathrm{~cm}$ of septal fluid collection surrounding them in the hernia sac during ultrasonography (USG), the patient was taken in for emergency operation. When the hernia sac was opened during the operation, a jejunum loop wrapped with omentum was observed (Figure 1). There were two round perforations in this loop, which were $0.4 \mathrm{~cm}$ in diameter and $10 \mathrm{~cm}$ apart (Figure 2). The biliary stent that had moved from the proximal perforation was detected and removed (Figure 3). After the primary repair of the perforations, the fascial defect was closed with an overlap. The patient was discharged free of problems on the seventh postoperative day.

\section{Discussion}

Many treatment methods are applied today to malignant or benign biliary strictures. Procedures that rely on percutaneous transhepatic or endoscopic methods are preferred more frequently than surgical interventions. In malignant cases in particular, morbidity rates, such as perioperative mortality and anastomotic stricture, are quite high. The fact that endoscopic and percutaneous biliary interventions are 


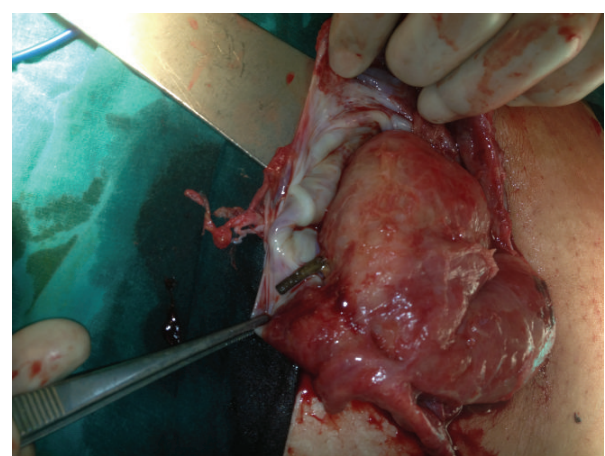

FIGURE 1

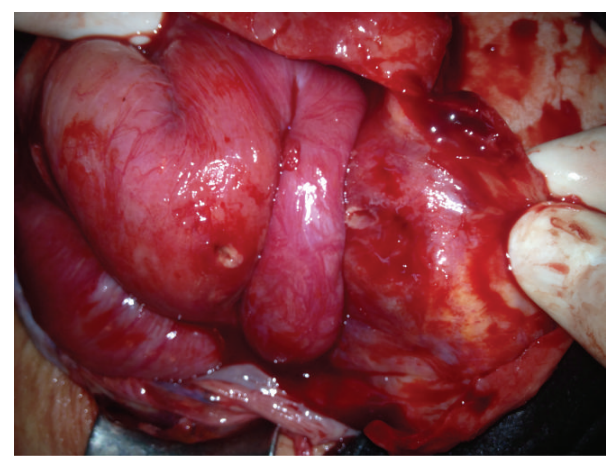

FIgURE 2

relatively less invasive methods ensures that they are more commonly preferred [2-5].

The transpapillary placement of plastic stents was first described by Soehendra and Reynders-Frederix [6] in 1979 and its use continues to increase today. The rates of complications arising from endobiliary stents have been reported to be between 8 and 10\%, mortality rates 1\%, and distal migrations up to $6 \%[5,7,8]$. The migration rate in plastic stents has been reported to be higher compared to metal stents [9]. It has been reported that the risk of migration is higher in stents placed due to benign causes compared to those placed due to malignant causes $[10,11]$. The reason for the more frequent occurrences of stent migration in benign diseases is explained by the greater growth in diameter of the biliary tract in relation to benign causes and the rapid decrease in inflammation after the stent. In malignant diseases, however, the migration rate is reported to be low due to stent fixation resulting from tumor growth $[1,10,11]$. While proximal migration of the stent has been associated with malignant strictures and stents that are wide and short, distal migration has been linked to benign strictures and ampullary stenosis [1]. Some authors suggest that, in order to reduce the risk of stent migration, rather than a single large stent, multiple smaller stents be placed instead [12]. Routine sphincterotomy during biliary stenting is not recommended due to the sphincter of Oddi tonus and valves may help in preventing distal migration [1].

The most frequently encountered problem with endoscopically placed biliary stents is that of restenosis, due to benign or malignant causes [13]. The proximal or distal

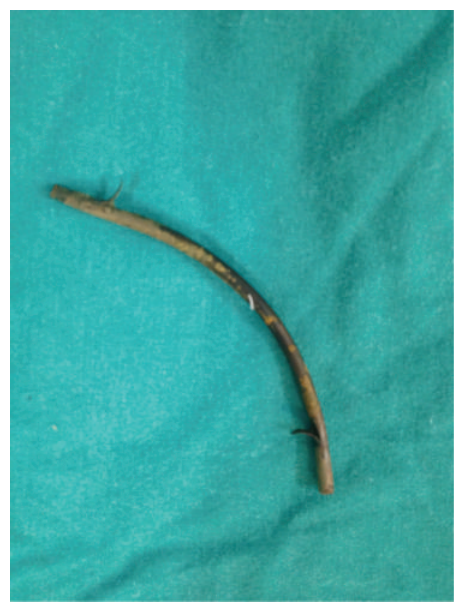

Figure 3

migration of the stent, on the other hand, is not very common [9]. It is reported that these stents, which undergo migration, are often expelled through natural means or remain in the intestinal tract without causing symptoms [1].

Although the intestinal migration of the choledochal stent is not uncommon, the extralumination of the stent within the intestinal lumen through the intestinal wall is a rare complication. Because it is fixed and " $C$ " shaped, the duodenum has been reported to be the location where stents most frequently extraluminate $[14,15]$. In addition, reasons such as adhesions that lead to diversion of the linear course of the intestinal tract, diverticula, and the formation of an intestinal protrusion into the hernia sac have also been reported as conditions that increase the likelihood of stent extralumination. Cases of colovesical fistulae [16], colovaginal fistulae [15], colocutaneous fistulae [17], small bowel perforations [18], and perforations within parastomal hernia [19] have been reported as a result of these pathologies causing extralumination. In the featured case, as well, the stent must have passed into the hernia sac from the protruding intestinal loops through the stages of wall contact, decubitus, perforation, and extralumination most likely due to the diversion of the lumen $[20,21]$.

We concluded that the stent, which was moving along smoothly within the intestinal lumen, was blocked from following its natural intestinal course when an intestinal "kinking," caused by reasons such as a hernia, diverticulitis, or adhesions, as in the case of our patient, or luminal pathologies, created a resistance to this thrust, after which the stent, left between these two forces, perforated the intestinal wall.

Consequently, endoscopic biliary instrumentation has been performed with increasing frequency recently, and, due to increased experience and improved technology, the number of patients who undergo a stent procedure is also increasing day by day. Accordingly, there is also a natural rise in complications associated with stents. Biliary stent migrations generally tend to be asymptomatic, despite being common. In patients with a history of a biliary stent that has been placed for any reason and the presence of acute abdominal symptoms, especially if a hernia is present, one must 
consider the possibility of intestinal perforations. Abdominal $\mathrm{X}$-rays and CT scans of the abdomen may aid in showing the stent in an ectopic location.

\section{Consent}

The patient described in the case report has given their informed consent for the case report to be published.

\section{Conflict of Interests}

All authors declare that they have no conflict of interests.

\section{References}

[1] J. F. Johanson, M. J. Schmalz, and J. E. Geenen, "Incidence and risk factors for biliary and pancreatic stent migration," Gastrointestinal Endoscopy, vol. 38, no. 3, pp. 341-346, 1992.

[2] A. C. Smith, J. F. Dowsett, R. C. G. Russell, A. R. W. Hatfield, and P. B. Cotton, "Randomised trial of endo-scopic stenting versus surgical bypass in malignant low bile duct obstruction," The Lancet, vol. 344, no. 8938, pp. 1655-1660, 1994.

[3] K. H. Barth, "Percutaneous biliary drainage for high obstruction," Radiologic Clinics of North America, vol. 28, no. 6, pp. 1223-1235, 1990.

[4] J. Deviere, S. Devaere, M. Baize, and M. Cremer, "Endoscopic biliary drainage in chronic pancreatitis," Gastrointestinal Endoscopy, vol. 36, no. 2, pp. 96-100, 1990.

[5] P. R. Mueller, J. T. Ferrucci Jr., S. K. Teplick et al., "Biliary stent endoprosthesis: analysis of complications in 113 patients," Radiology, vol. 156, no. 3, pp. 637-639, 1985.

[6] N. Soehendra and V. Reynders-Frederix, "Palliative biliary duct drainage. A new method for endoscopic introduction of a new drain," Deutsche Medizinische Wochenschrift, vol. 104, no. 6, pp. 206-207, 1979.

[7] N. P. Lenzo and G. Garas, "Billiary stent migration with colonic diverticular perforation," Gastrointestinal Endoscopy, vol. 47, no. 6, pp. 543-544, 1998.

[8] F. C. T. Smith, H. J. O'Connor, and R. Downing, "An endoscopic technique for stent recovery used after duodenal perforation by a biliary stent," Endoscopy, vol. 23, no. 4, pp. 244-245, 1991.

[9] J. Görich, N. Rilinger, S. Krämer et al., "Displaced metallic biliary stent: technique and rationale for interventional radiologic retrieval," American Journal of Roentgenology, vol. 169, no. 6, pp. 1529-1533, 1997.

[10] M. B. Jendresen and L. B. Svendsen, "Proximal displacement of biliary stent with distal perforation and impaction in the pancreas," Endoscopy, vol. 33, no. 2, article 195, 2001.

[11] W. C. Culp, T. C. McCowan, R. P. Lieberman, T. C. Goertzen, R. F. LeVeen, and T. G. Heffron, "Biliary strictures in liver transplant recipients: treatment with metal stents," Radiology, vol. 199, no. 2, pp. 339-346, 1996.

[12] B. Bui, V. Oliva, G. Ghattas et al., "Percutaneous removal of biliary stent after acute spontaneous duodenal perforation," CardioVascular and Interventional Radiology, vol. 18, pp. 20002003, 1995.

[13] K. F. Binmoeller, U. Seitz, H. Seifert, F. Thonke, S. Sikka, and N. Soehendra, "The Tannenbaum stent: a new plastic biliary stent without side holes," American Journal of Gastroenterology, vol. 90, no. 10, pp. 1764-1768, 1995.
[14] A. Humar, P. T. Barron, A. S. C. Sekar, and A. Lum, "Pancreatitis and duodenal perforation as complications of an endoscopically placed biliary stent," Gastrointestinal Endoscopy, vol. 40, no. 3, pp. 365-366, 1994.

[15] A. M. Blake, N. Monga, and E. M. Dunn, "Biliary stent causing colovaginal fistula: case report," Journal of the Society of Laparoendoscopic Surgeons, vol. 8, no. 1, pp. 73-75, 2004.

[16] A. Wilhelm, C. Langer, G. Zoeller, R. Nustede, and H. Becker, "Complex colovesicular fistula: a severe complication caused by biliary stent migration," Gastrointestinal Endoscopy, vol. 57, no. 1, pp. 124-126, 2003.

[17] R. G. Figuerias, M. O. Echart, A. G. Figuerias et al., "Colocutaneous fistulae relating to the migration of a biliary stent," European Journal of Gastroenterology \& Hepatology, vol. 13, pp. 1251-1253, 2001.

[18] B. M. Mistry, M. A. Memon, R. Silverman et al., "Small bowel perforation from a migrated biliary stent," Surgical Endoscopy, vol. 15, no. 9, p. 1043, 2001.

[19] J. M. Levey, "Intestinal perforation in a parastomal hernia by a migrated plastic biliary stent," Surgical Endoscopy, vol. 16, no. 11, pp. 1636-1637, 2002.

[20] U. Klein, F. Weiss, and O. Wittkugel, "Migration of a biliary Tannenbaum stent with perforation of sigmoid diverticulum," RoFo, vol. 173, p. 1057, 2001.

[21] T. A. Ruffolo, G. A. Lehman, S. Sherman, R. Aycock, and A. Hayes, "Biliary stent migration with colonic diverticular impaction," Gastrointestinal Endoscopy, vol. 38, no. 1, pp. 81-83, 1992. 


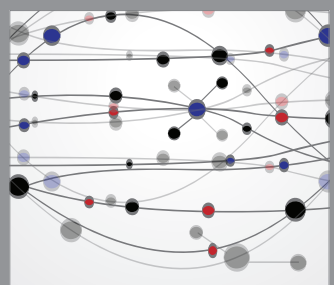

The Scientific World Journal
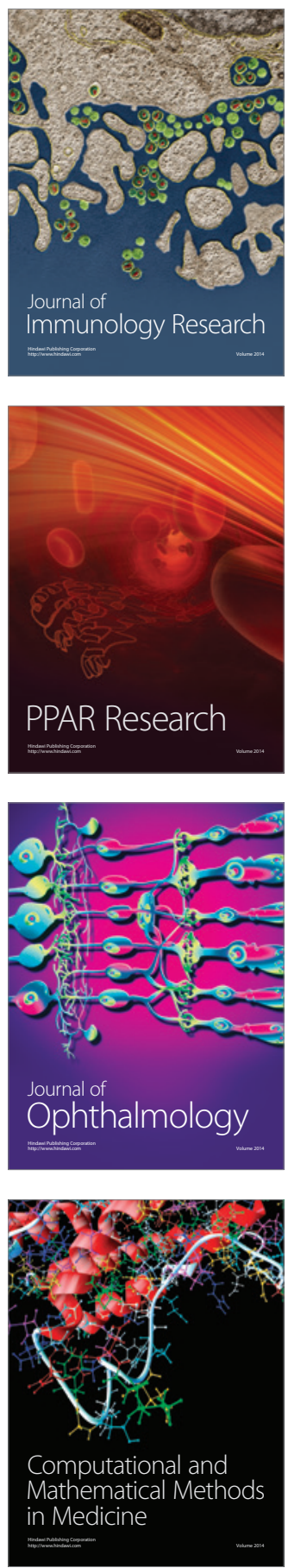

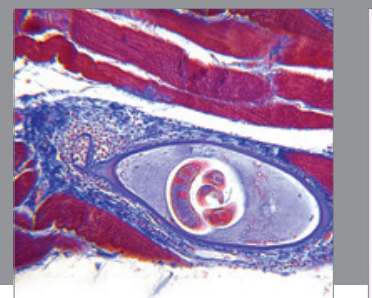

Gastroenterology

Research and Practice
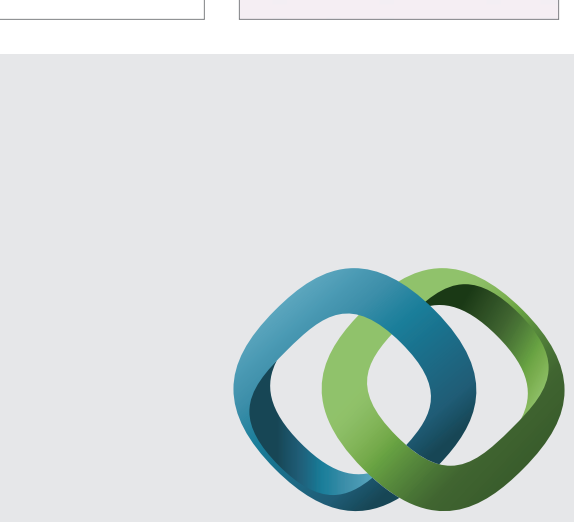

\section{Hindawi}

Submit your manuscripts at

http://www.hindawi.com
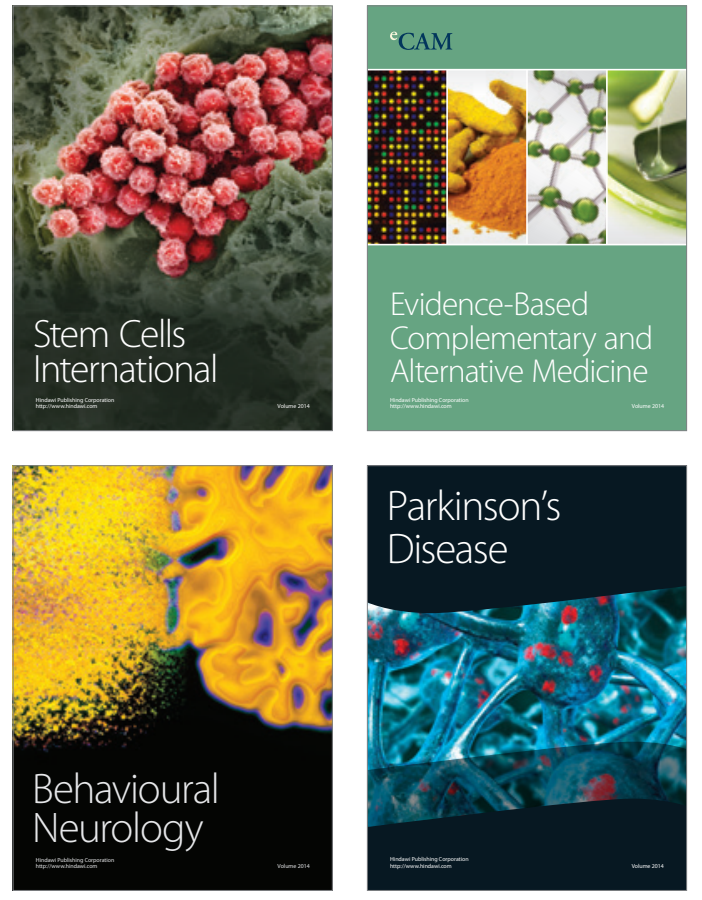
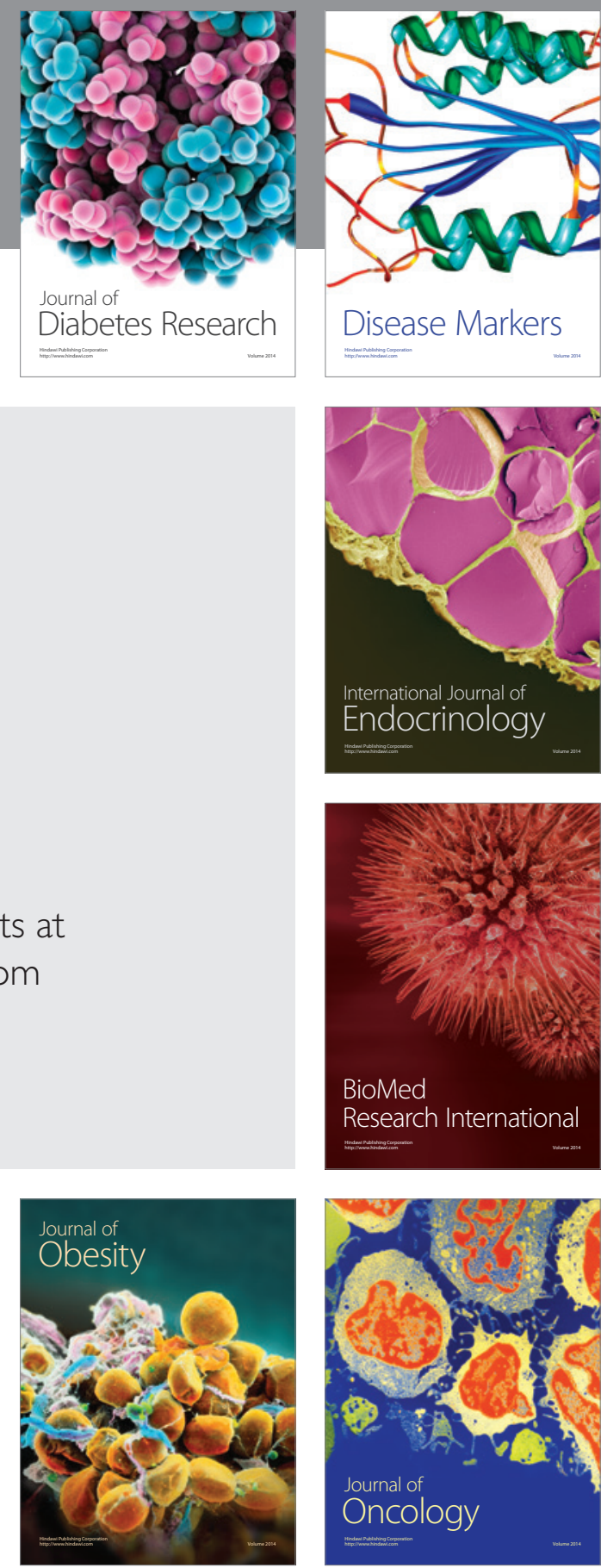

Disease Markers
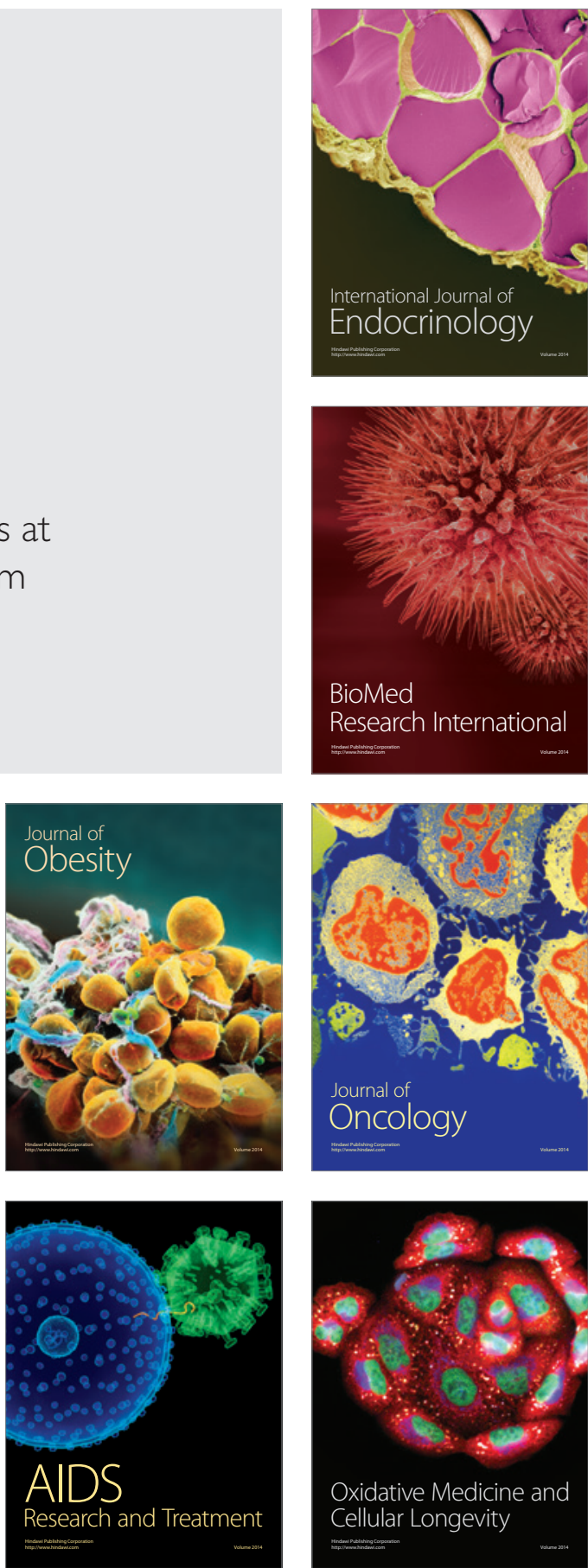